\title{
Genetic Bases of Stuttering: The State of the Art, 2011
}

\author{
Shelly Jo Kraft ${ }^{\mathrm{a}}$ Ehud Yairib, ${ }^{\mathrm{b}}$

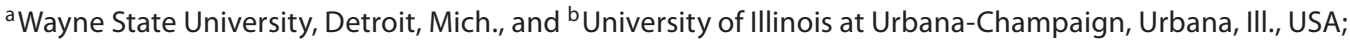 \\ 'Tel Aviv University, Tel Aviv, Israel
}

Key Words

Stuttering $\cdot$ Genetics $\cdot$ Fluency $\cdot$ Genes

\begin{abstract}
Objective: The literature on the genetics of stuttering is reviewed with special reference to the historical development from psychosocial explanations leading up to current biological research of gene identification. Summary: A gradual progression has been made from the early crude methods of counting percentages of stuttering probands who have relatives who stutter to recent studies using entire genomes of DNA collected from each participant. Despite the shortcomings of some early studies, investigators have accumulated a substantial body of data showing a large presence of familial stuttering. This encouraged more refined research in the form of twin studies. Concordance rates among twins were sufficiently high to lend additional support to the genetic perspective of stuttering. More sophisticated aggregation studies and segregation analyses followed, producing data that matched recognized genetic models, providing the final 'go ahead' to proceed from the behavior/statistical genetics into the sphere of biological genetics. Recent linkage and association studies have begun to reveal contributing genes to the disorder. Conclusion: No definitive findings
\end{abstract}

have been made regarding which transmission model, chromosomes, genes, or sex factors are involved in the expression of stuttering in the population at large. Future research and clinical implications are discussed.

Copyright $\odot 2011$ S. Karger AG, Basel

\section{Historical Perspectives}

Similarities in traits between children and their parents, as well as further removed ancestors, struck people thousands of years ago, inviting speculations as to the nature of inheritance. In ancient Greece, Aristotle offered that inheritance is transmitted through the father's semen and the mother's menstrual blood that are mixed in the womb. The mother provides unformed matter that the semen then forms into an individual of some determined kind [1]. Genetics, the scientific study of genes, what they are and how they control heredity characteristics in living organisms, however, began much later with the groundbreaking work of Gregor Mendel [2] on pea breeding experiments that took place in the middle of the 19th century. Stuttering, too, has been recognized for thousands of years and subjected to the opinions of the ancient Greeks. Aristotle [3], for example, opined that

\section{KARGER}

Fax +4161306 1234

E-Mail karger@karger.ch

www.karger.com
(C) 2011 S. Karger AG, Basel

1021-7762/12/0641-0034\$38.00/0

Accessible online at:

www.karger.com/fpl
Shelly Jo Kraft

Communication Sciences and Disorders

Wayne State University

60 Farnsworth Street, Detroit, MI 48202 (USA)

Tel. +1 313577 3339, E-Mail kraft@wayne.edu 
stuttering is due to difficulties in tongue movement from the position of one sound to the next, as well as to nervousness, whereas Hippocrates [4] thought it resulted from dryness of the tongue. Although one may reasonably assume that familial stuttering was observed even in the far past, it appears that those ancients failed to connect stuttering with inheritance.

The numerous ideas expressed since then about the possible cause of stuttering present an extremely wide range of general orientations and viewpoints. These include faulty anatomical structures (e.g., abnormally large tongue, unusual brain morphology), faulty physiology (e.g., breathing patterns, lack of cerebral dominance), psychopathology (i.e., neuroticism), faulty central language formulation and planning of sequential speech movement, and acquired (learned) abnormal speech patterns (e.g., listeners punished or reinforced normal speech disfluencies). Reviews of these and other theoretical notions about stuttering can be found in Bloodstein and Bernstein-Ratner [5].

One can comfortably assume that awareness of the familial trend of stuttering has been around for a long time. It is more than likely that many people who stutter could not avoid noticing that some, or many, of their relatives also stuttered. Likewise, normally fluent people were probably aware that several family members of their nextdoor neighbors stutter. Certainly scholars of stuttering must have been aware of familial patterning in stuttering, especially when relevant accounts began appearing in the scientific literature. It is surprising, therefore, that except for one, all of the above-cited theoretical notions did not include a link to the familial trait of the disorder. The one that did address the phenomenon, Johnson's $[6,7]$ diagnosogenic theory, took pains to interpret it as just another example of psychosocial phenomena (e.g., religion or political preference) that family members tend to share and pass down through generations, and which, at least on the surface, are not considered to be genetically inherited. Specifically, it was suggested that a history of stuttering in the family generates strong emotions that drive parents of young children to both act and react in ways that interfere with the child's normal speech. This, Johnson $[6,7]$ suggested, eventually led to stuttering. His view had worldwide acceptance that persisted for more than 30 years. Nevertheless, the decades between the 1930s and the end of the 20th century saw gradual, yet significant, advancements in the scientific pursuit of the genetics of stuttering.

Our objective here is to outline the journey from point A to the current state of the art by briefly describing and summarizing the systematic, logical order of four phases of scientific progress in the genetics of stuttering. More detailed critical reviews of methodologies, especially of the first three phases, can be found in Andrews et al. [8], Felsenfeldt [9], Yairi et al. [10], and Yairi and Ambrose [11].

\section{Phase I: Familial Incidence}

Laypersons' and clinicians' observations of the familial trend of stuttering were put to more rigorous examinations in the 1930s. In one of the earliest controlled studies of this phenomenon, Bryngelson and Rutherford [12] examined the disorder's incidence in the families of 74 probands ${ }^{1}$ who stuttered, aged $4-16$ years, comparing it with that of an identical number of matched normally fluent children. They found that $46 \%$ of those who stuttered had a family history of stuttering, compared with $18 \%$ of the control sample. Nearly 60 years and 28 studies later, a review of the literature led Yairi et al. [10] to the conclusion that this general finding held firm. Although the full range of stuttering probands having a familial history of stuttering was between 20 and $74 \%$, the majority of reported findings fell in a narrower range of $30-60 \%$. In comparison, in families of normally fluent controls, the overall incidence of stuttering ranged from 1.3 to $42 \%$ with most of the studies reporting incidence lower than $10 \%$. Shortly after, in a much larger study, Wepman [13] reported that $68.8 \%$ of 250 stuttering probands had additional familial stuttering versus only $15.6 \%$ in matched control families. His thoughts at the time concerning the clinical implications of the finding are of interest in displaying a genetic perspective: 'It may be that stammering inherited duplex, from both sides of the parental line, is permanent and cannot be successfully treated, or that stammering inherited simplex, from one parental branch, is amenable to treatment... It is true, however, that if stammering be inherited, treatment can effect [sic] only the present manifestation of the disorder and cannot effect [sic] the cause' [13, p. 203]. A summary of the findings of the 28 studies mentioned above [10] is seen in figure 1 .

That familial stuttering can be extensive is seen in the Ambrose et al. [14] sample of 69 preschool children who stuttered, $45 \%$ of whom had afflicted relatives in the im-

\footnotetext{
1 In genetic studies that investigate multiple family members, the term proband is used to denote an individual affected with the disorder of interest by which the rest of the family is referenced and identified.
} 


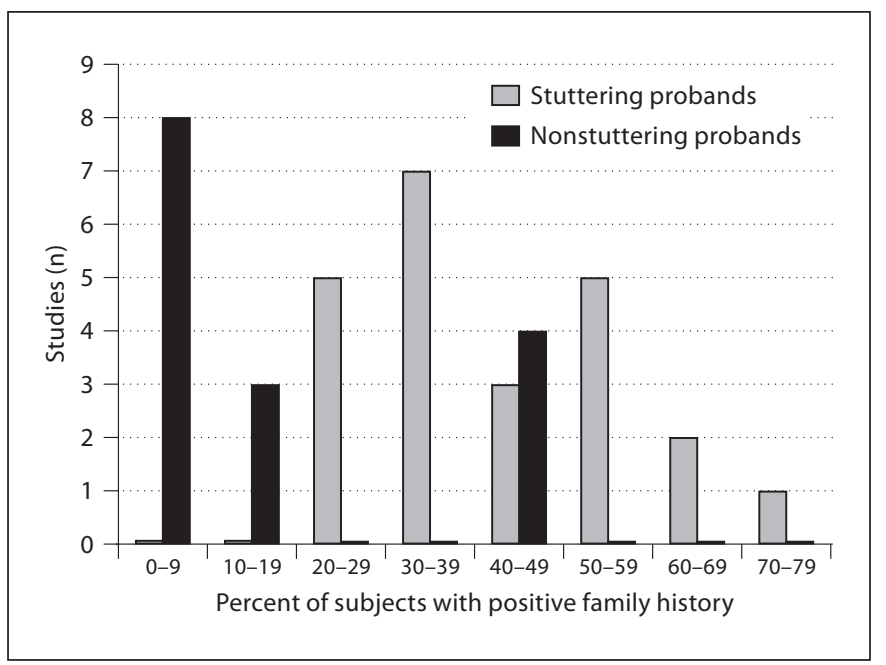

Fig. 1. Summary of studies of familial incidence of stuttering. stutters (e.g., a second cousin, great aunt, etc.). Furthermore, if stuttering is familial, small families have reduced chances for full expression of the disorder. Compare, for example, a constellation where the father of a proband stutters and has only 1 brother with no children to a proband whose stuttering father has 3 brothers, each of whom has 3 children [15].

Unfortunately, such data were not obtained, or not considered, in many past studies. In spite of limitations, this line of research served to redirect the then-prevailing belief about the heritability of stuttering, that regarded it as a psychosocially transmitted disorder. This redirection motivated scholars to proceed by employing more appropriate methodologies to pursue indications for the genetic basis of stuttering. Chronologically, such further pursuit initially followed the path of twin studies.

\section{Phase II: Twin Studies}

Twin studies seek to derive heritability estimates, that mediate family (parents and siblings), increasing to $71 \%$ when members of the extended family (parents, siblings, grandparents) were included. The latter findings are particularly illustrative of the phenomenon because data were carefully obtained soon after the onset of stuttering (ages 2-4 years), when many of the relatives were still alive and/or evidence of past stuttering was more readily available, verifiable, and updated through follow-up interviews over several years. In 2005, Yairi and Ambrose [11] reported a positive family history of stuttering for $69 \%$ of 123 families, a figure that strongly supports the upper end of previous estimates.

Information regarding percentages of people who stutter having relatives who also stutter as compared to percentages among normally fluent control subjects, however, is far from constituting scientific evidence for the genetics of stuttering. In addition to classic problems with differences in the definition of stuttering (or not providing informants with a definition), lack of personal interviews for verification, false-positive, and especially false-negative identification of individuals who either currently stutter or those who had recovered [10], variables such as family size and the distinct familial class (e.g., fathers, mothers, brothers, and sisters) of the afflicted relatives are of great importance. Obviously, it makes a substantial difference when a proband reporting familial stuttering has 1 stuttering relative in a family of only 4 members as compared to 1 relative who stutters in a family of 16. Similarly, it matters if a proband has a father who stutters or whether he/she has a distant relative who is, separate the respective roles of genetics and environment in determining or influencing a certain trait, in our case, stuttering. This objective is accomplished by comparing the presence and characteristics of stuttering in groups of identical (paternal, monozygotic) twin pairs who share nearly $100 \%$ of their deoxyribonucleic acid (DNA), with groups of nonidentical (fraternal, dizygotic) pairs who share only $50 \%$ of their DNA, just like other nontwin siblings. Genetic bases of stuttering would receive considerable support if both members of an identical pair stutter because they share the same genetic makeup. This is especially true if, at the same time, concordance for stuttering in nonidentical twin pairs appears to be much lower. Differences between identical twins in the expression of stuttering (or another disorder), however, are assumed to be due to environmental effects. In the case of nonidentical twins, similarities between the pair members are taken as a reflection of their common environmental influences. Note, however, that there is evidence that twins appear to be more susceptible to a variety of disorders, such as anorexia nervosa [16] and autism [17] when compared to singletons. Therefore, some cases of stuttering among twins may be yet another manifestation of this general difference between twinning and singletons, thus perhaps somewhat blurring the effect of genetics.

Two studies represent the early work in this area. In 1937, Berry [18] reported a survey of 1,000 families in which greater incidence of twinning was found in fami- 
lies that included people who stutter than in families free from stuttering. Moreover, in the twinning families, stuttering occurred more frequently in the twins than in single sibling members, raising the logical query if the converse to the above (which looked for twinning in families with stuttering) is true: is stuttering incidence more frequent in twinning families than in families without duplicate births? In a follow-up investigation, Berry [19] examined 250 twin pairs for the occurrence of stuttering. The findings were positive. She concluded that the number of children who stuttered among the total number of children in these families exceeded statistical expectations. Furthermore, 1 twin child in 11 stuttered, whereas in single siblings only 1 in 35 stuttered. Her conclusion and genetic-wise speculations from 75 years ago are of interest: 'The results of this study indicate that twinning and stuttering also tend to go together... Is it possible that the nervous dysfunction which obtains in stuttering is part and parcel of the same factor in the germ plasm responsible for multiple birth? If the genetic complex is responsible for the retarded axiate growth at a critical moment in the embryo's life, then it may be responsible at the same time for the retardation in the neural patterns necessary for integrated speech. To carry the argument further back, the factor in the germ plasm producing twins may be the gene establishing an abnormal biochemical relationship, favorable to the retardation of a single axiate production, unfavorable to normal speech' $[19, \mathrm{pp}$. $55-$ 56].

Berry [19], however, did not proceed to compare the incidence of stuttering in monozygotic and dizygotic twins. The first to examine the concordance for stuttering in the two members of mono- and dizygotic twin pairs were Nelson et al. [20] at the University of Illinois. In a sample of 200 twin pairs, 40 pairs had at least $1 \mathrm{mem}$ ber who stuttered, 10 were identical with 9 affected cotwins. In contrast, among the 30 dizygotic pairs with stuttering, only 1 showed concordance.

For a while, twin research progressed slowly with inconsistent findings. On the one hand, Graf [21] reported stuttering in 18 of 552 twin pairs with only 3 concordant pairs, 1 monozygotic and 2 dizygotic. On the other hand, Godai et al. [22] identified many more concordant monozygotic twins (83\% of 22 pairs) than dizygotic twins ( $11 \%$ of 41 pairs). An important milestone in this research path took place a few years later with the publication of Howie's [23] study. This investigator employed tighter procedures in classifying twins as identical and her sample included 30 same-sex twin pairs. Howie [23] found concordance for stuttering in $63 \%$ of the monozygotic pairs as compared with only $19 \%$ concordance among dizygotic pairs. There was also moderate resemblance in core stuttered speech characteristics (e.g., syllable repetitions) within monozygotic pairs [24]. These findings provided resounding support to the notion that genetics plays an important role in stuttering. Still, as Felsenfeldt [9] noted, the small sample size limited its usefulness for further quantitative genetic analyses, such as estimates of heritability.

Two subsequent investigations that utilized the Australian twin registry of several thousand pairs found lower concordance percentages for stuttering than reported in the past but supported the general trend of considerably higher concordance in identical than in nonidentical twin pairs. In the first one, Andrews et al. [8] studied 50 identical twin pairs of which $20 \%$ showed concordance for stuttering whereas only $5.4 \%$ of 37 nonidentical pairs had such concordance ${ }^{2}$. One weakness of the study was that participants were identified through questionnaires without verification. In spite of the small percentage of concordance, an important finding was that the difference between the two types of twins indicated a strong genetic effect for stuttering. A model fitting procedure attributed $71 \%$ of the variance in liability to stuttering to additive genetic variance, with the remaining $29 \%$ attributed to unique environmental factors. The second study, conducted by Felsenfeld et al. [25], was based on direct interviews with 38 identical and 53 nonidentical pairs. The respective concordance for stuttering was 45 and $15 \%$.

In 2005, Ooki [26] investigated 1,896 Japanese twin pairs, reporting concordance for stuttering in monozygotic and dizygotic pairs at 52 and $12 \%$, respectively. The study mirrored the findings of Andrews et al. [8] by estimating the genetic contribution to stuttering at $80 \%$ for males and $85 \%$ for females. At about the same time, the Illinois study of the development of stuttering $(n=123)$ reported only 5 sets of twins, 2 identical and 3 fraternal. In all sets both children stuttered but severity and duration of the stuttering disorder varied [11]. Two years later, Dworzynski et al. [27] used longitudinal data from the Twins Early Development Study to identify 1,085 children who stuttered. In the recovered group $(n=950)$, concordance for stuttering among identical twins was $40 \%$ compared with $20 \%$ among fraternal twins. In the persis-

\footnotetext{
2 Felsenfeldt [9] commented that the low number of twins also suggested that the incidence of stuttering is probably not significantly higher than that in singletons as previously reported by Berry [19] and Nelson et al. [20].
} 
Table 1. Percent concordance in stuttering twins

\begin{tabular}{lclr}
\hline Study & $\begin{array}{l}\text { Dizygotic } \\
\%\end{array}$ & $\begin{array}{l}\text { Monozygotic } \\
\%\end{array}$ & $\begin{array}{l}\text { Pairs } \\
\mathrm{n}\end{array}$ \\
\hline Godai et al. [22] & 11 & 83 & 63 \\
Howie [23] & 19 & 63 & 30 \\
Andrews et al. [8] & 5.4 & 20 & 87 \\
Felsenfeld et al. [25] & 15 & 45 & 91 \\
Ooki [26] & 12 & 52 & 1,896 \\
Dworzynski et al. [27] & 12 & 32 & 1,100 \\
van Beijsterveldt et al. [28] & 31 & 57 & 10,500 \\
\hline
\end{tabular}

van Beijsterveldt et al. [28] reported concordance for twins with 'probable stuttering'.

tent group $(n=150)$, concordance was 19 and $0 \%$, respectively. When recovered and persistent groups were combined, concordance was 32\% for monozygotic and $12 \%$ for dizygotic twin pairs. Most recently, an investigation of stuttering and high nonfluency was conducted using 10,500 five-year-old Dutch twin pairs [28]. This study used parent questionnaires that did not use the term 'stuttering', but asked about frequency of repetitions, prolongations, and blocks observed in their children. Responses were categorized as 'probable stuttering' or 'high nonfluency'. Concordance for probable stuttering across genders was $31 \%$ for dizygotic and $57 \%$ in monozygotic pairs. These results in concert with the results from the other twin studies support stronger phenotype inheritance in identical twins. Table 1 summarizes data reported in modern era twin studies.

When considering the evidence for a genetic etiology of stuttering, one cannot overlook the fact that the twin study approach did not reveal perfect concordance rates for stuttering even in monozygotic twins. Whereas the aforementioned data suggests that stuttering is not $100 \%$ gene-based, the trends in concordance rates between fraternal and identical twins favor strong genetic components to stuttering while also allowing for the possible presence of environmental factors still to be determined. Overall, however, the additional information gathered through twin studies strengthened the motivation to further pursue the genetics of stuttering. As will be discussed below, the next research phase focused on exploring the mode of stuttering inheritance.

\section{Phase III: Family Aggregation}

Substantial evidence continued to accrue for the genetic transmission of stuttering during a third research phase in which the familial aggregation method was employed. Historically, family aggregation research in stuttering began in the early 1960s, several decades after the family incidence and twin studies appeared on the scene, and for a while, all three overlapped in time. In contrast to the two previous research lines, family aggregation studies require the identification of stuttering in the various classes of family relatives, as well as according to gender. This allows for assessment of the respective risk for each class or category. Using detailed probands' pedigrees (family trees), such studies typically cover first- and second-degree relatives, including grandparents, uncles, and cousins, with each individual marked as having ever stuttered, never stuttered, or unknown. The most important feature of these studies is that the statistics applied (e.g., segregation analysis) allow for the evaluation of how well the data fit with one or more of the following existing transmission models: (1) no genetic components, (2) multifactorial polygenic (MFP, environmental factors + many genes), (3) single major locus (SML, one or a few main genes are involved, no environmental factor), and (4) mixed (both MFP and SML components).

Positive statistical evidence that a major gene or several major genes are involved in the transmission of the disorder was necessary to justify the eventual next phase of molecular (biological) genetic research, that is linkage analysis [29].

To date, only three investigations of family aggregation have been carried out. The pioneer study conducted by Kay [30] in Britain and published as part of the Andrews and Harris' [31] landmark book of the same year included 213 probands and their families representing a wide age-range from early childhood to adulthood. Kay [30] reported three important findings. First, the incidence of stuttering among first-degree relatives of probands was $13.65 \%$, substantially above the expected $5 \%$ for the general population [31,32]. This finding, obtained through the much improved methodology, confirmed those of older reports reviewed earlier under phase I, lending more credible backing to the proposition of genetic factors underlying stuttering. Second, the probability of risk for stuttering differed greatly among the various classes of probands' relatives as shown in table 2 . The strong trend for more male relatives to be at risk for stuttering reinforces the already familiar sex factor in stuttering (higher incidence among males than among females). 
Kay [30] also found that the greatest risk for stuttering was for male relatives of females who stutter, whereas the lowest risk rested with female relatives of males who stutter. Third, and most importantly, the data indicated that the distributional pattern of familial stuttering had the best fit with a disorder controlled by a primary gene with contributions from other genes (the SML model). The data, however, could also fit a model of purely polygenic inheritance (the MFP model).

Being the first of its kind, Kay's [30] work took the pursuit of the genetics of stuttering a substantial step forward. The match with a genetic model provided a powerful signal that invited further aggressive genetic research. Despite this new promising information, only a very small number of studies followed the lead and it took more than a decade for the next major contribution to appear in print. This time it was Kenneth Kidd and his colleague at Yale University who proposed and tested genetic models, attempting to map out and explain the transmission of stuttering as a family trait. The Yale Family Study of Stuttering, another milestone in the field, had a large database of 600 first-degree relatives of mostly adult probands who exhibited chronic stuttering. Several reports on the familial incidence of stuttering [33-37] also looked at family type (e.g., neither parents ever stuttered, or, only father ever stuttered), probands' children, relationship to stuttering severity [38], natural recovery [39], and other aspects [see summary in ref. 15]. Generally, the Yale team mirrored several of Kay's [30] findings by reporting (a) an overall incidence among probands' first-degree relatives substantially above the expected ( 15 and 5\%, respectively), (b) appreciably higher risk for stuttering among male relatives (fathers and brothers) than among female relatives (mothers and sisters) for probands of both sexes, and (c) higher risk for stuttering among all categories of relatives of female probands than relatives of male probands. With the improved family aggregation methodology, these data provided broad-based support to the view that familial stuttering, as well as the large male-to-female ratio among those affected, are genetically based. Kidd posited that the male-to-female ratio can probably be explained by a lower threshold for males, with females requiring more genetic 'loading' for stuttering to be expressed. The data were consistent with vertical transmission (inheritance of an allele ${ }^{3}$ or condition from either the father or mother) with sexmodified expression. The sex-modified transmission of stuttering was consistent with all three models: multifactorial polygenic, single major locus, and mixed $[33,34,40]$.

After another interval of more than a decade, a third familial aggregation investigation conducted at the Uni-
Table 2. Percentage of family class members who stuttered

\begin{tabular}{lc}
\hline Class & Percent \\
\hline Mothers & 6.8 \\
Fathers & 19.1 \\
Sisters & 8.4 \\
Brothers & 20.3 \\
\hline
\end{tabular}

Based on the families of 213 probands who stuttered, following Kay [30].

versity of Illinois was published by Ambrose et al. [14]. A key difference from the previous two aggregation studies was the employment of an unbiased sample drawn from families of 69 preschool children recruits soon after stuttering onset, before natural recovery took place. Most probands in the earlier studies were considerably older and, hence, represented mainly the small minority $(25 \%$ or less) of those initially diagnosed with stuttering who had continued to stutter for many years (the other $75 \%$ typically vanish due to natural recovery). Again, the team's findings pointed to genetic factors to stuttering. Among other findings (a) more than two thirds of the young probands reported positive family history of the disorder, (b) the incidence of stuttering was considerably higher among first- than second-degree relatives, (c) the familial distribution of stuttering indicated that the gender factor ${ }^{4}$ in stuttering appeared to be related to familial history of stuttering, and, most importantly, (d) the first statistically significant evidence was presented that transmission of a single major genetic locus best accounted for the transmission of stuttering in families [14]. This finding was particularly encouraging because it implied that one or a few primary genes, rather than many genes, might be isolated to account for stuttering. There was also evidence for multifactorial/polygenic transmission of susceptibility to stuttering.

The last advance in this phase extended the research concerned with the possibility that stuttering is not a uniform disorder but covers various subtypes, a possibility

\footnotetext{
3 An allele refers to a single version of a DNA sequence in a given location when there are two or more known versions for that same position.

4 Initially, the authors found different, even reversed, patterns of stuttering in the male and female classes of probands' relatives than those reported in the Kay [30] and Kidd [33-37] studies. In a later publication, however, as their sample increased to 123 probands, the Illinois team [11] reported patterns similar to Kay's [30] and Kidd's [33-37].
} 
raised sporadically for a long time but one that until recently has received minimal research attention [see reviews in ref. 41, 42]. An early reference to a genetic basis for stuttering subtypes [13] entertained the idea that stuttering therapy outcome depends on whether a person inherits stuttering through the line of only one parent or through the lines of both parents.

Of special interest are specific extensions within two of the family aggregation studies that explored genetic differences between people exhibiting persistent chronic stuttering and those who recovered naturally, without treatment. Cox and Kidd [39] asked whether recovery could be a genetically milder subtype of stuttering, an independent disorder, or even nongenetic. Although no meaningful patterns were found, the authors admitted that, inasmuch as all the families were identified through adults with persistent stuttering, the sample was biased. Approximately 15 years later, Ambrose et al. [45] reported longitudinal data that traced children who recovered naturally and those who developed persistent stuttering. Three questions were posed: (1) Is there a sex effect in recovery from stuttering? (2) Is persistence or natural recovery from stuttering heritable? (3) If recovery appears to be heritable, are persistent and recovered stuttering independent disorders or a unitary one where recovered stuttering is a genetically milder form of persistent stuttering? Their answers to the first two questions were positive. As for the third one, they concluded that recovery is not a milder form of stuttering, nor do the two types of stuttering appear to be independent disorders. The data, however, suggested that both forms of stuttering share a common major gene, but persistent stuttering involves additional polygenic components. Segregation analyses supported these conclusions and provided statistical evidence for both a single major locus and polygenic component for persistent and recovered stuttering. Viswanath et al. [46] performed a segregation analysis where the Mendelian model was selected for best fit over other genetic and nongenetic models. This model was further refined to suggest an autosomal dominant major gene effect (meaning only one gene is needed from one parent to inherit the condition) in stuttering transmission that is influenced by (a) gender and (b) stuttering status of parents. Most recently in this phase, in a final report, Yairi and Ambrose [11] affirmed their earlier findings, reporting that whereas $88 \%$ of children who persisted had positive familial history of stuttering, only $65 \%$ of children who recovered naturally had such history $(\mathrm{n}=123)$.

\section{Phase IV: Biological Genetics}

The gradually mounting and improving evidence in support of strong genetic components to stuttering yielded by the family incidence, twin, and family aggregation investigations produced the justification needed to proceed with the fourth and most direct phase in the pursuit of the genetics of stuttering, namely biological genetics. Two main approaches have been employed to identify gene-disorder or gene-trait relationships: linkage and association. Both use genetic markers to analyze variations within either families (by means of linkage) or entire populations (by means of association).

Genetic markers are stretches of DNA that exhibit variations among individuals and populations [47]. These variations can be seen as the genetic sequences of nucleotides in DNA. In general, these segments of DNA are designated as 'markers' because they have been previously identified for their properties and known locations. They serve as points of reference, a genetic road map. Markers can be anything from entire chromosomes to genes, to single inconsequential nucleotide substitutions. The markers used in linkage and association studies, however, are often identified by polymorphisms, that is, DNA at a given site with more than one possible sequence. Typically, these markers have either two alleles (often simple mutations) or multiple alleles. Most polymorphisms, whether two-allele or multiallelic, have no consequence to the organism, meaning they are not responsible for any traits, but may be used in studies to localize the small number of genetic variations that actually affect disease to the correct region of the chromosome on which disease alleles reside. Although the analysis of pedigrees in a segregation analysis can provide information pertaining to the genetic model underlying a disease or trait, diagnosis and treatment depend on knowing which specific genes have polymorphisms contributing to the disease.

Linkage analysis traces the inheritance pattern of genes as they are passed from generation to generation. The technique exploits the phenomenon of coinheritance, that is, certain alleles that are physically close together on the same chromosome tend to be inherited together. Alleles close to a marker will be coinherited with it. In other words, they are genetically linked as reflected in the term linkage analysis. Hence, the objective of linkage analysis is to identify a piece of DNA in a known chromosomal location (near a marker) that is inherited by all family members affected by the disorder being investigated (e.g., stuttering), but is not inherited by anyone who is unaffected. Because linkage analysis uses markers 
to define relatively large segments of genetic material likely to contain the sought-after polymorphism that causes or contributes to disease, further analysis is often required to identify the specific relevant gene polymorphism.

\section{Linkage Analysis Research in Stuttering}

To date, several studies have employed linkage analysis to investigate families with several members who stutter, targeting any chromosomal regions prevalent in affected cases. This research activity was conducted by only two teams, one at the United States National Institutes of Health (NIH) and the other at the University of Illinois and the University of Chicago ${ }^{5}$. The initial findings obtained with this method were reported by the NIH team [48]. Buccal swabs were collected from 226 members (188 affected) of 68 families with familial multiple incidence of stuttering. All participants were recruited from the general population of North America and Europe. Scanning 392 markers across the genome, statistical support at a low to moderate level for linkage tied to stuttering was found on several regions of chromosome 18 .

A second investigation [49] used linkage analysis to study 46 highly inbred families from Pakistan, each including several members who stuttered. Using similar tissue material (buccal swabs), they genotyped 144 stuttering (affected) and 55 nonstuttering (unaffected) individuals. Evidence of linkage associated with stuttering was found on chromosomes 1, 5, 7, and 12. Additional analysis performed on chromosome 12 led this team to suggest that an unspecified locus on the long arm of chromosome 12 'may contain a gene with a large effect in this sample' [49, p. 647]. This finding, however, should be viewed with caution because in a highly inbred sample it is possible that such results reflect a common mutational origin for stuttering specific to these families. The families may have different genetic components underlying stuttering than those present in genetically diverse populations.

The next step in linkage analysis research was taken by investigators from the Illinois team [50]. They reported on linkage mapping studies in 100 families of European descent ascertained in the US, Sweden, and Israel. These families included 252 individuals exhibiting persistent stuttering, 45 individuals classified as recovered from stuttering and 19 individuals too young to classify.

\footnotetext{
5 The NIH team was led by Dr. D. Drayna and the Illinois team by Drs. N. Cox, N. Ambrose, and E. Yairi.
}

Using blood samples, primary genotyping analyses identified moderate evidence for linkage for the broader diagnosis of 'ever-stuttered' (including both persistent and recovered stuttering) on chromosome 9. The investigators took the analysis a step further, looking separately at several subgroups within their sample. An indication, although somewhat weaker, for linkage for persistent stuttering only was found on chromosome 15 whereas for those who had a history of natural recovery linkage was identified on chromosome 2. A separate analysis yielded the strongest and the only genome-wide significant findings whereby sex-specific linkage was identified on chromosome 7 for males, and with even greater significance on chromosome 21 for females. Hence, an additional contribution of the study was its support for the sex effects as genetic components to stuttering. Additional findings indicated that stuttering may result from the contribution of several chromosomal combinations, such as 9 and 2, or 7 and 12, suggesting a genetic basis for stuttering subtypes.

In 2007 [51], genotyping was performed on a founder population (the Hutterites from South Dakota) that reported 48 stuttering members in a 232-person family. Results of genome-wide linkage mapping in this family yielded nominal evidence for linkage with stuttering on chromosomes 3,9 , and 13 . When the investigators conducted a meta-analysis combining the 105 families from their earlier study [50] with the Hutterite samples, additional regions supporting linkage were found on chromosomes 2 and 5 . In linkage investigations very large segments of DNA, usually containing several genes, are implicated when a statistically significant region is found on a chromosome. Hence, it is difficult to say, with any certainty, what specific genes might be the actual candidate for genetic association with a trait or disease without taking a closer look at smaller regions, segments, and/or genes. A summary of linkage studies is presented in table 3. Only limited overlap can be seen across studies (5 chromosomes are listed under more than one study). In addition, it should be noted that the chromosomes implicated in more than one study, and/or twice in the same study, did not contain overlapping regions of linkage significance, but two separate areas on the same chromosome.

\section{Gene-Specific Investigations}

As discussed above, linkage studies typically cover several or many genes and large regions of DNA with the objective of identifying chromosomal areas where candidate genes for a trait or disease may be located. Some- 
Table 3. Summary of linkage studies

\begin{tabular}{lll}
\hline Study & $\begin{array}{l}\text { Chromosome with } \\
\text { most significant region }\end{array}$ & $\begin{array}{l}\text { Other chromosomes } \\
\text { with regions of interest }\end{array}$ \\
\hline Shugart et al. [48] & 18 & $1,2,10,13$ \\
Riaz et al. [49] & 12 & $1,5,7,12$ \\
Suresh et al. [50] & 9,15, and conditionally 2 & $\begin{array}{l}\text { male specific on } 7, \text { female specific on 21 } \\
\text { Wittke-Thompson et al. [51] }\end{array}$ \\
\hline
\end{tabular}

times, however, it is desired to perform a candidate gene analysis that probes smaller specific locations, looking for specific genes that are already suspected of involvement. Clues as to where to look emerge from a priori assumptions of the trait of interest, or from sufficient existing knowledge of the physiological or biochemical characteristics of the disease to point to a gene's (or genes') potential involvement. Methodology for candidate gene analysis typically includes the amplification ${ }^{6}$ of chromosomal regions of interest, identification of polymorphisms in the genes or the sequencing of neighboring regions, genotyping a control population, and, finally, analysis of associations between alleles and the trait of interest. Two investigations have been conducted in this category.

Research on the co-occurrence of stuttering and other disorders has shown that between 4 and $26 \%$ of children who stutter also exhibit attention deficit/hyperactivity disorder (ADHD) [52-54]. Based on this information, Lan et al. [55] investigated specific regions of DNA containing known genes (SLC6A3 and DRD2) associated with ADHD. The SLC6A3 gene is involved in dopamine transport and was identified in 2005 in a screening of children diagnosed with ADHD [56]. DRD2 encodes the receptor for dopamine (D2) in the brain. Studies have shown that individuals who carry an alternative sequence (haplotype) for this gene demonstrated poorer executive functioning than control subjects [57]. Some suggested that this gene may also underlie ADHD [58]. The Lan et al. [55] study is the first to specifically investigate the role of SLC6A3 and DRD2 in stuttering. They recruited 112 Mandarin-speaking Han Chinese who stuttered, and matched them with normally speaking controls. A total of five regions were amplified and replicated for extraction of genomic data. No statistically significant differences between groups for the SLC6A3 gene were found.

\footnotetext{
6 Amplification is a step in genotyping that makes multiple identical copies of a DNA sequence so that it may be studied.
}

There was, however, a significant variation within the DRD2 gene. The investigators suggested that the finding supports the notion of dopamine excess involved in stuttering introduced by Wu et al. [59] and Maguire et al. [60, 61]. The sample size, however, was small and investigators acknowledged a need for a large scale case-control replication study.

The most recent development in the genetics of stuttering was also conducted by the NIH-based team. Kang et al. [62] employed a linkage-based candidate gene analysis to reinvestigate regions on chromosome 12 reviewed earlier [49]. One member from each of the same bloodrelated and/or inbred Pakistani families $(n=46)$ was included in the new analysis. These subjects, along with an additional 77 unrelated affected Pakistani subjects and 270 affected North American and British subjects were tested for mutations on chromosome 12 , suspected as the site of genes contributing to their persistent stuttering.

To target potential candidate genes, a strong candidate region first had to be identified. Saliva samples from 7 participants in the 2005 study [49] that supported linkage on chromosome 12, and samples from 3 newly recruited control subjects were sequenced. The results were discouraging as they failed to reveal any likely genes associated with persistent stuttering. Next, an additional twopoint linkage analysis was performed that included every member of the PKST72 family. The investigators were able to replicate significant linkage signals but at more proximal locations on the q-arm of chromosome 12 than originally identified. DNA sequencing and analysis of this large region (covering the span of 87 known genes) in 7 related Pakistani subjects who stutter and 3 unrelated controls did not reveal any significant mutations associated with stuttering. There were, however, numerous polymorphisms identified in this region that were specific to the affected members of the Pakistani families tested. These variants were unfortunately found at high frequencies among the nonstuttering, unrelated Pakistani population and were thus disregarded for candidacy. 
Once again, the investigators took a closer look at family PKST72. In this round, a mutation in the GNPTAB gene was identified in most of the stuttering individuals of PKST72 with only 3 affected family members not having the apparent risk allele. GNPTAB is responsible metabolically for encoding alpha and beta subunits of GNPT ( $\mathrm{N}$-acetylglucosamine-1-phosphate transferase). Kang et al. [62] were able to identify the same mutation in this gene in 5 other affected individuals from the Pakistani population, and in 1 North American person of AsianIndian ancestry. Additionally, three mutations of another gene, NAGPA on chromosome 12, were observed in 6 affected North American-British subjects but not in any member of the Pakistani population. These genes encode signaling enzymes that direct lysosomal metabolism in the brain and body.

Because these findings have received worldwide publicity as the first genes identified to underlie stuttering, they obviously invite close scrutiny. Indeed, two responses to Kang et al. [62] have been published. Fisher [63, p. 751] expressed reservations concerning the study's conclusion, stating that 'The GNPTAB, GNPTG and NAGPA variants were found in only a small proportion of cases, together accounting for 21 of 393 cases in unrelated affected subjects'. Furthermore, the absence of typical symptoms related to skeletal, respiratory, and cardiovascular abnormalities associated with the gene led Fisher [63] to question its compatibility with what is known about stuttering, stating that '...the nature of the implicated biologic pathway - an unlikely culprit to explain stuttering' (p. 751). Büchel and Watkins [64] also questioned the suitability of the gene to explain stuttering in light of advances in the knowledge about the disorder, pointing out that Kang et al. [62] did not relate the gene they isolated to neuroimaging studies that revealed abnormalities in the white matter of people who stutter.

In our own evaluation, the Kang et al. [62] study offers little information that can be generalized to the population at large of people who stutter. It appears to us that its findings, although encouraging, should be viewed with reservations for the following reasons:

(1) Chromosome 12 was not identified as a potential site for genes associated with stuttering in any other linkage study concerned with stuttering $[48,50,51]$.

(2) There were no indications for genes located on chromosome 12 in a recent genome-wide association study (GWAS) just completed at the University of Illinois and the University of Chicago [65] (see next).

(3) The findings relied heavily on one 'large' Pakistani family (PKST72, $\mathrm{n}=101$ ) known to be highly inbred.
Within this family, 3 members stuttered who were not carriers of the GNPTAB mutation.

(4) The GNPTAB risk allele was found in only 6 additional people who stutter out of 316 unrelated affected subjects who were not members of the PKST72 family. This frequency amounts to only $4 \%$ of this subsample, raising questions about applicability of the findings to the population at large of people who stutter.

(5) The three mutations of the NAGPA gene were identified in only 7 cases out of the possible 393 of the affected cases, that is, only $1 \%$.

Overall, these figures are too small to positively associate the genes with stuttering. Major limitations of linkage studies exist as a result of the relatively low statistical power for samples of complex disorders. The power is strongly influenced by multiple genes and the often hundreds of chromosomal regions shared among family members not related to the disorder of interest. It can be difficult to narrow the linkage signal in these samples sufficiently to identify a causative gene [66]. In addition, the role of the lysosomal targeting pathway is only speculative and has not been proven to cause stuttering.

Until successful biological studies are conducted that conclusively tie lysosomal function to speech fluency, the co-occurrence of these variants with stuttering in a very small proportion of the subjects studied cannot be construed as causation.

\section{Association Studies}

Genetic association studies are based on the assumption that heritable risk for a trait or disease is mostly attributable to a relatively small number of genetic variants $[67,68]$. They are designed to identify such variants (particular alleles) that are found more frequently in affected individuals than in unaffected individuals. Such alleles either directly affect risk of disease or are in linkage disequilibrium ${ }^{7}$. This systematic analysis of genetic variations is expected to lead to the localization of causal genes [67] without the need for prior hypothesis regarding genetic associations with the disorder of interest [68]. One association strength is that it screens 'without any prior predilection for specific regions, genes, or variants thereof' $[69$, p. 161]. In fact, this type of study has been referred to as a 'hypothesis-free' approach $[66,67]$, making it ideal for this complex disorder.

\footnotetext{
Linkage disequilibrium refers to alleles that are found more frequently than expected by random chance combinations and are located very close to alleles that directly affect risk of disease.
} 
In general, association studies are more powerful than linkage studies for the identification of genes contributing to the risk for complex diseases [70]. A GWAS is an approach that involves scanning markers across complete sets of DNA, or genomes, of many unrelated people to find genetic variations associated with a particular disease. A GWAS allows for very large numbers (nearly 1 million) of polymorphisms across the entire human genome to be analyzed for variants $[71,72]$. The method has recently been used with success to investigate disorders such as autism, Tourette syndrome, and specific language impairment.

Inasmuch as no definite conclusion has been reached on which transmission model, chromosomes, genes, alleles, or sex factors are involved in the expression of stuttering, GWAS appears to be the method of choice for future research. In fact, scientists at the University of Illinois, in conjunction with the University of Chicago, have recently completed the first study that employed this method aimed at identifying replicable candidate genes that influence the risk of individuals for persistent stuttering [65]. To maximize the chance of success, subjects with clearly defined persistent phenotypes were chosen as affected cases. Candidate genes were selected via identification of regions demonstrating allele frequency differences between the experimental and control groups. The initial results indicate 10 significant candidate genes to be associated with persistent developmental stuttering. In addition, functional significance was found with relevance of these genes to three categories pertaining to (a) neural development, (b) neural function, and (c) behavior. Currently, these data are undergoing additional analyses.

\section{Discussion}

\section{Future Directions}

The future of genetic research in stuttering faces several challenges. Perhaps the most critical is that of replication. Other complex disorders have begun to hurdle this obstacle with significant success. A good lesson can be learned from the wide publicity given to early linkage studies of schizophrenia and bipolar disorder for results that were later unable to be replicated. Statistically speaking, a very large number of participants (i.e., matched case-controls, sibling pairs, families) are required to detect linkage to a gene that may only have a fractional affect on observable behavior or the phenotypic trait being studied. Such requirements pose difficulties for any one investigator to independently recruit a sufficient number of subjects. Indeed, researchers in other scientific disciplines have heeded this reality and have initiated collaborative genetic consortium projects. Investigators must soon realize that the larger good of the cause must outweigh any difficulties in collaborative sharing. It will undoubtedly be a challenge to share resources and data, but the benefits could be the crucial step needed to definitively identify the genes responsible for stuttering. As reviews by Felsenfeldt [9] and Yairi et al. [10] point out, issues concerning the lack of consistent phenotype definitions and diagnostic protocols have confounded early genetic work. Collaborative data sharing would result in multiple research sites using identical diagnostic procedures and measurements, matching definitions of phenotypes, and a shared contribution to a collective bank of samples in an effort to achieve enough statistical power to make some conclusive discoveries. The data obtained from multiple institutions, all performing different studies, and comprised of diverse samples of case-controls, families, and sibling pairs, should not be competitive, but complementary. Currently, administrators of the United States' NIH are in the process of defining rules for largescale collaborative sharing. From the Institutes' perspective, inasmuch as considerable funds granted for researching complex diseases are specifically allocated to the procurement and diagnosis of subjects, maximizing the funding's yield is a priority.

Finally, as Ambrose et al. [45] cautioned, we should recognize that in spite of our tremendous progress in uncovering the genetics of stuttering, the nature and role of environmental factors should remain as an important subject for future research because these factors may be more readily modified to assist recovery, reduce symptoms, and aid in adjustment. As they stated: 'Just as in heart disease, some individuals are genetically at high risk, but environmental modifications involving diet and exercise can be of great benefit' [45, p 578]. We know that DNA is both inherited and environmentally responsive. The function of genes in the body reflects the interaction between hereditary and environmental information. When trying to associate phenotypic traits with actual genes, it can become very difficult to parse out concrete evidence for causation when several genes acting independently of each other can all potentially contribute to the same phenotypic behaviors and traits. Biophysiological studies will help to identify environmental factors and gene function. Such studies are often considered as phase II of the research plan after replicable genes have been identified. 


\section{Clinical Considerations}

Genetic research has obvious potential for clinical applications. It provides an alternative to the top-down approach not infrequently taken to diagnose and treat stuttering. Historically, philosophers, scientists, and clinicians have used the behaviors and traits of stuttering to guide the search for biophysical mechanisms by which to logically explain the disorder, without the eventual identification of organic components contributing to the root cause. Although commendable progress has been made in various aspects of stuttering research, the current absence of a definitive etiology has slowed advancements in the clinical sphere of the disorder, without a major breakthrough in treatment for a long time. Genetic research lends a bottom-up approach, with ample promises for innovative clinical management, including diagnosis, prognosis, and treatment. By identifying the genes associated with stuttering, it would be possible to map out their biophysiological contributions to normal and disrupted fluency, thus facilitating a much better understanding of the disorder. In addition, Yairi et al. [10, p. 782] suggest that genetic findings '...will have far reaching impact on early intervention and subsequent decision concerning cost effective treatment for stuttering children... treatment will become increasingly more targeted for those who need it most'. Furthermore, the emotional burden that plagues many parents of children who stutter, having misconceptions about their behavior being the cause of the disorder as suggested by the diagnosogenic [7] and psychogenic [73] theories, can be diminished with increased knowledge of the major genetic contributions involved. Again according to Yairi et al. [10, p. 782], '...if we ultimately find an underlying genetic component to susceptibility to chronic stuttering, then persistent stuttering will not necessarily be a reflection of a failure of treatment, will, or ability, but an expression of a genetic predisposition. The discovery that stuttering severity is less determined by heritability than the disorder itself $[24,38]$ has already established a more optimistic outlook for therapeutic success. Genetic findings are also likely to facilitate attempts of developing pharmaceutical treatment approaches of stuttering currently under way $[74,75]$. In this respect, Alzheimer's disease provides an encouraging prospect for the potential clinical implications. The first causative genetic mutation was discovered in 1991 that led scientists to the disease's underlying pathophysiology [76]. The mutation was in a gene responsible for the metabolism of beta-amyloid (a fibrous protein that contributes to cell structure in the brain) [77]. Within 10 years, several amyloid therapeutic strategies were being tested and today have yielded some positive outcomes [78-80]. Perhaps looking farther into the future, gene therapies might also be applied to stuttering. This approach involves, for example, inserting a gene into a patient's cells, replacing a mutated gene that causes disease with a healthy copy of the gene.

\section{Conclusion}

Continuing in the pursuit of definitive answers, qualitative biological genetic approaches are scientifically logical to pursue. Studies which produce replicable findings congruent with sound theories and evidence would be invaluable to the clinical and scholastic future of stuttering.

\section{Acknowledgments}

This article was written upon invitation to Ehud Yairi at the University of Illinois Stuttering Research Program and was originated there. Shelly Jo Kraft was formerly affiliated with this program.

\section{References}

1 Henry D: Aristotle on the mechanisms of inheritance. J Hist Biol 2006;39:425-455.

$\checkmark 2$ Mendel G: Versuche über Pflanzen-Hybriden. J Hered 1951;42:3-47.

3 Ross MA, Hon LD: The Works of Aristotle. Oxford, Cambridge University Press, 1927.

4 Schaffer EJ: Part of our heritage. ASHA 1966; 167-168.

5 Bloodstein O, Bernstein-Ratner N: A Handbook on Stuttering, ed 6. New York, Thomson-Delmar, 2008.
6 Johnson W: A study of the onset and development of stuttering. J Speech Hear Disord 1942;7:251-257.

7 Johnson W, et al: The Onset of Stuttering Minneapolis, University of Minnesota Press, 1959.

-8 Andrews G, Morris-Yates A, Howie P, Martin N: Genetic factors in stuttering confirmed. Arch Gen Psychiatry 1991;48:10341035 .
-9 Felsenfeldt S: Progress and needs in the genetics of stuttering. J Fluency Disord 1996; 21:77-103.

10 Yairi E, Ambrose N, Cox N: Genetics of stuttering: a critical review. J Speech Hear Res 1996;39:771.

11 Yairi E, Ambrose N: Early Childhood Stuttering. Austin, Pro-Ed, 2005.

12 Bryngelson B, Rutherford B: A comparative study of laterality of stutterers and non-stutterers. J Speech Hear Disord 1937;2:15-16. 
13 Wepman JM: Familial incidence of stammering. J Hered 1939;30:207.

14 Ambrose NG, Yairi E, Cox N: Genetic aspects of early childhood stuttering. J Speech Hear Res 1993;36:701-706.

15 Kidd K: Stuttering as a genetic disorder; in Curlee R, Perkins W (eds): Nature and Treatment of Stuttering. San Diego, College Hill, 1984, pp 149-169.

- 16 Bulik CM, Sullivan PF, Tozzi F, Furberg H, Lichtenstein P, Pedersen NL: Prevalence, heritability, and prospective risk factors for anorexia nervosa. Arch Gen Psychiatry 2006;63:305-312

17 Greenberg DA, Hodge SE, Sowinski J, Nicoll D: Excess of twins among affected sibling pairs with autism: implications for the etiology of autism. Am J Hum Gen 2001;69:10621067.

18 Berry MF: Twinning in stuttering families. Hum Biol 1937;9:329-346.

19 Berry MF: A common denominator in twinning and stuttering. J Speech Hear Disord 1938;3:51-57.

20 Nelson SF, Hunter N, Walter M: Stuttering in twin types. J Speech Hear Disord 1945;10: 335-343.

21 Graf OI: Incidence of stuttering among twins; in Johnson W, Leutenegger R (eds): Stuttering in Children and Adults. Minneapolis, University of Minnesota Press, 1955, pp 381-386.

22 Godai U, Tatarelli R, Bonanni G: Stuttering and tics in twins. Acta Genet Med Gemellol (Roma) 1976;25:369-375.

23 Howie PM: Concordance for stuttering in monozygotic and dizygotic twin pairs. J Speech Hear Res 1981;24:317-321.

24 Howie PM: Intrapair similarity in frequency of disfluency in monozygotic and dizygotic twin pairs containing stutterers. Behav Genet 1981;11:227-238.

-25 Felsenfeld S, Kirk KM, Zhu G, Statham DJ, Neale MC, Martin NG: A study of the genetic and environmental etiology of stuttering in a selected twin sample. Behav Genet 2000; 30:359-366.

26 Ooki S: Genetic and environmental influences on stuttering and tics in Japanese children. Twin Res Hum Genet 2005;8:69-75.

-27 Dworzynski K, Remington A, Rijsdijk F, Howell P, Plomin R: Genetic etiology in cases of recovered and persistent stuttering in an unselected longitudinal sample of young twins. Am J Speech Lang Pathol 2007;16: 169-178.

28 van Beijsterveldt CEM, Felsenfeld S, Boomsma DI: Bivariate genetic analysis of stuttering and nonfluency in a large sample of 5 -year-old twins. J Speech Lang Hear Res 2010;53:609-619.

-29 Suarez BK, Cox NJ: Linkage analysis for psychiatric disorders. I: Basic concepts. Psychiatr Dev 1985;3:219-243.
30 Kay D: The genetics of stuttering; in Andrews G, Harris M (eds): The Syndrome of Stuttering. London, The Spastic Society Medical Education and Information Unit, 1964, pp 132-143.

31 Andrews G, Harris M: The Syndrome of Stuttering. Clinics Dev Med. London, Spastics Society Medical Education, 1964, No 17.

-32 Mansson H: Childhood stuttering: incidence and development. J Fluency Disord 2000;25: 47-57.

33 Kidd KK: A genetic perspective on stuttering. J Fluency Disord 1977;2:259-269.

34 Kidd KK: Genetic models of stuttering. J Fluency Disord 1980;5:187-201.

35 Kidd K, Heimbuch R, Records M: Vertical transmission of susceptibility to stuttering with sex-modified expression. Proc Natl Acad Sci USA 1981;78:606-610.

36 Kidd KK, Kidd JR, Records MA: The possible causes of the sex ratio in stuttering and its implications. J Fluency Disord 1978;3:13-23.

37 Kidd K, Reich T, Kessler S: A genetic analysis of stuttering suggesting a single major locus. Genetics 1973;74(part 2):S137.

38 Kidd KK, Heimbuch RC, Records MA, Oehlert G, Webster RL: Familial stuttering patterns are not related to one measure of severity. J Speech Hear Res 1980;23:539-545.

39 Cox NJ, Kidd KK: Can recovery from stuttering be considered a genetically milder subtype of stuttering? Behav Genet 1983;13 129-139.

40 Cox NJ, Kramer PL, Kidd KK, Rao DC: Segregation analyses of stuttering. Genet Epidemiol 1984;1:245-253.

-41 Seery CH, Watkins RV, Mangelsdorf SC, Shigeto A: Subtyping stuttering. II: Contributions from language and temperament. J Fluency Disord 2007;32:197-217.

42 Yairi E: Subtyping stuttering I: a review. J Fluency Disord 2007;32:165-196.

43 Janssen P, Kloth S, Kraaimaat F, Brutten G: Genetic factors in stuttering: a replication of Ambrose, Yairi, and Cox's 1993 study with adult probands. J Fluency Disord 1996;21: 105-108.

44 Poulos MG, Webster WG: Family history as a basis for subgrouping people who stutter. J Speech Hear Res 1991;34:5-10.

45 Ambrose NG, Cox NJ, Yairi E: The genetic basis of persistence and recovery in stuttering. J Speech Lang Hear Res 1997;40:567580.

46 Viswanath N, Lee HS, Chakraborty R: Evidence for a major gene influence on persistent developmental stuttering. Hum Biol 2004;76:401-412.

47 McGuffin P, Owen MJ, Gottesman II: Psychiatric Genetics and Genomics. Oxford, Oxford University Press, 2005.

48 Shugart YY, Mundorff J, Kilshaw J, Doheny K, Doan B, Wanyee J, Green ED, Drayna D: Results of a genome-wide linkage scan for stuttering. Am J Med Genet 2004;124:133135.
49 Riaz N, Steinberg S, Ahmad J, Pluzhnikov A, Riazuddin S, Cox NJ, Drayna D: Genomewide significant linkage to stuttering on chromosome 12. Am J Hum Genet 2005;76: 647-651.

50 Suresh R, Ambrose N, Roe C, Pluzhnikov A, Wittke-Thompson JK, Ng MCY, Wu X, Cook EH, Lundstrom C, Garsten M: New complexities in the genetics of stuttering: significant sex-specific linkage signals. Am J Hum Genet 2006;78:554-563.

51 Wittke-Thompson JK, Ambrose N, Yairi E, Roe C, Cook EH, Ober C, Cox NJ: Genetic studies of stuttering in a founder population. J Fluency Disord 2007;32:33-50.

52 Arndt J, Healey EC: Concomitant disorders in school-age children who stutter. Lang Speech Hear Serv Sch 2001;32:68-78.

53 Healey EC, Reid R: ADHD and stuttering: a tutorial. J Fluency Disord 2003;28:79-93.

54 Riley G, Riley J: A revised component model for diagnosing and treating children who stutter. Contemp Issues Commun Sci Disord 2000;27:188-199.

-55 Lan J, Song M, Pan C, Zhuang G, Wang Y, Ma W, Chu Q, Lai Q, Xu F, Li Y: Association between dopaminergic genes (SLC6A3 and DRD2) and stuttering among Han Chinese. J Hum Genet 2009;54:457-460.

56 Mazei-Robison MS, Couch RS, Shelton RC, Stein MA, Blakely RD: Sequence variation in the human dopamine transporter gene in children with attention deficit hyperactivity disorder. Neuropharmacology 2005;49:724736 .

57 Reuter M, Peters K, Schroeter K, Koebke W, Lenardon B: The influence of the dopaminergic system on cognitive functioning: a molecular genetic approach. Behav Brain Res 2005;164:93-99.

58 Mazei-Robison MS, Bowton E, Holy M, Schmudermaier M, Freissmuth M, Sitte HH, Galli A, Blakely RD: Anomalous dopamine release associated with a human dopamine transporter coding variant. J Neurosci 2008; 28:7040-7046.

-59 Wu JC, Maguire G, Riley G, Lee A, Keator D, Tang C, Fallon J, Najafi A: Increased dopamine activity associated with stuttering. Neuroreport 1997;8:767-770.

60 Maguire GA, Riley GD, Franklin DL, Maguire ME, Nguyen CT, Brojeni PH: Olanzapine in the treatment of developmental stuttering: a double-blind, placebo-controlled trial. Ann Clin Psychiatry 2004;16:63-67.

61 Maguire GA, Yu BP, Franklin DL, Riley GD: Alleviating stuttering with pharmacological interventions. Expert Opin Pharmacother 2004;5:1565-1571

62 Kang C, Riazuddin S, Mundorff J, Krasnewich D, Friedman P, Mullikin JC, Drayna D: Mutations in the lysosomal enzyme-targeting pathway and persistent stuttering. $\mathrm{N}$ Engl J Med 2010;362:677-685. 
63 Fisher SE: Genetic susceptibility to stuttering. N Engl J Med 2010;362:750-752.

-64 Büchel C, Watkins KE: Genetic susceptibility to persistent stuttering. $\mathrm{N}$ Engl J Med 2010;362:2226-2227.

65 Kraft SJ: Genome-Wide Association Study of Persistent Developmental Stuttering; PhD thesis University of Illinois, Urbana-Champaign, 2010.

-66 Pearson TA, Manolio TA: How to interpret a genome-wide association study. JAMA 2008; 299:1335-1344.

-67 Hunter DJ, Altshuler D, Rader DJ: From Darwin's finches to canaries in the coal mine mining the genome for new biology. N Engl J Med 2008;358:2760-2763.

68 Hirschhorn JN, Daly M: Genome-wide association studies for common diseases and complex traits. Nat Rev Gen 2005;6:95-108.

-69 Kitsios GD, Zintzaras E: Genomic convergence of genome-wide investigations for complex traits. Ann Hum Genet 2009;73: 514-519.

70 Risch N, Merikangas K: The future of genetic studies of complex human diseases. Science 1996;273:1516-1517.

71 Li M, Li C, Guan W: Evaluation of coverage variation of SNP chips for genome-wide association studies. Eur J Hum Genet 2008;16: 635-643.
72 Wang TH, Wang HS: A genome-wide association study primer for clinicians. Taiwan J Obstet Gynecol 2009;48:89-95.

73 Murphy AT, Fitzsimons RM: Stuttering and Personality Dynamics: Play Therapy, Projective Therapy, and Counseling. New York, Ronald Press, 1960.

74 Stager S, Calis K, Grothe D, Block M, Berensen N, Smith P, Braun A: Treatment with medications affecting dopaminergic and sertonergic mechanisms: effects on fluency and anxiety in persons who stutter. J Fluency Disord 2005;30:319-335.

75 Maguire G, Franklin D, Vatakis NG, Morgenshtern E, Denko T, Yaruss JS, Spotts C, Davis L, Davis A, Fox P, Soni P, Blomgren M Silverman A, Riley G: Exploratory randomized clinical study of pagoclone in persistent developmental stuttering: the examining pagoclone for persistent developmental stuttering study. J Clin Psychopharmacol 2010; 30:48-56.

-76 Chartier-Harlin M, Crawford F, Houlden H, Warren A, Hughes D, Fidani L, Goate A, Rossor M, Roques P, Hardy J, Mullan M: Early-onset Alzheimer's disease caused by mutations at codon 717 of the beta-amyloid precursor protein gene. Nature 1991;353:844846.
77 Irvine GB, El-Agnaf OM, Shankar GM, Walsh DM: Protein aggregation in the brain: the molecular basis for Alzheimer's and Parkinson's diseases. Mol Med 2008;14:451464.

78 Matsouka Y, Saito M, LaFrancois J, Saito M, Gaynor K, Olm V, Casey E, Yifan L, Shiratori C, Lemere C, Duff K: Novel therapeutic approach for the treatment of Alzheimer's disease by peripheral administration of agents with an affinity to beta-amyloid. J Neurosci 2003;23:29-33.

79 Dodel RC, Du Y, Depboylu C, Hampel H, Frolich L, Haag A, Hemmeter U, Paulsen S, Teipel SJ, Brettschneider S, Spottke A, Nolker C, Moller HJ, Wei X, Farlow M, Sommer $\mathrm{N}$, Oertel WH: Intravenous immunoglobulins containing antibodies against beta-amyloid for the treatment of Alzheimer's disease. J Neurol Neurosurg Psychiatry 2004; 75:1472-1474.

80 Cherny RA, Atwood CS, Xilinas ME, Gray $\mathrm{DN}$, Jones WD, McLean CA, Barnham KJ, Volitakis I, Fraser FW, Kim Y-S, Huang X, Goldstein LE, Moir RD, Lim JT, Beyruether K, Zheng H, Tanzi RE, Masters CL, Bush AI: Treatment with a Copper-Zinc chelator markedly and rapidly inhibits beta-amyloid accumulation in Alzheimer's disease transgenic mice. Neuron 2001;30:665-676. 